\title{
Benign gastric carcinoid tumor with hypergastrinemia followed up for 12 years
}

\author{
Kimiyuki Hori ${ }^{1,3}$, Hirokazu Fukui ${ }^{2}$, Johji Imura ${ }^{3}$, Takane Kojima ${ }^{4}$, Mikio Fujita ${ }^{3}$, Hitoski Kawamata ${ }^{3}$, \\ Tsutomu Chiba ${ }^{2}$, and TAKAhiro FuJIMORI ${ }^{3}$ \\ ${ }^{1}$ Hori Gastro-Intestinal Clinic, Kakogawa, Hyogo, Japan \\ ${ }^{2}$ Department of Gastroenterology and Hepatology, Kyoto University Graduate School of Medicine, Kyoto, Japan \\ ${ }^{3}$ Department of Pathology, Dokkyo University School of Medicine, 880 Kitakobayashi, Mibu, Shimotsuga, Tochigi 321-0293, Japan \\ ${ }^{4}$ Kojima Clinic, Himeji, Japan
}

\begin{abstract}
Gastric carcinoid tumors associated with chronic atrophic gastritis type $A$ have been reported to show good prognosis, because invasion and metastasis are rare. We report a case of gastric carcinoid tumor associated with hypergastrinemia that showed no malignant changes for 12 years. A 15-year-old man with abdominal discomfort underwent endoscopic examination. A polypoid lesion was detected on the atrophic mucosa of the fundus, and was diagnosed as a carcinoid tumor. Serological examination revealed a high level of anti-parietalcell antibody, suggesting that the patient had chronic atrophic gastritis type $A$. The tumor was treated by endoscopic mucosal resection. Follow-up examinations were performed for 12 years, but showed no recurrence. This case confirms that gastric carcinoid tumors associated with chronic atrophic gastritis type A may have a good prognosis.
\end{abstract}

Key words Hypergastrinemia · Carcinoid tumor · Prognosis · Autoimmune gastritis

\section{Introduction}

Most gastric carcinoid tumors are associated with hypergastrinemia caused by chronic atrophic gastritis type A (CAG-A) [1,2], multiple endocrine neoplasia (MEN) type I syndrome [3,4], or Zollinger-Ellison syndrome $[4,5]$. Therefore, we need to characterize gastric carcinoid tumors to decide on suitable therapy for them. Recently, gastric carcinoid tumors associated with CAG-A have been reported to show good prognosis compared with that shown by other types of

Offprint requests to: T. Fujimori

Received: June 30, 2000 / Accepted: September 22, 2000 carcinoid tumors [6-9]; however, the optimal treatment of this condition is still a matter of debate. In this study, we report a patient with gastric carcinoid tumor with hypergastrinemia caused by $\mathrm{CAG}-\mathrm{A}$; the tumor was treated by endoscopic mucosal resection and showed no recurrence or metastasis for 12 years.

\section{Case report}

A 51-year-old man with abdominal discomfort was referred to Hori Gastro-Intestinal Clinic in 1987. He had no remarkable medical history. Routine laboratory findings revealed no abnormalities on urine, peripheral blood, and serum examinations. Endoscopic examination of the upper gastrointestinal tract demonstrated non-antral atrophic gastritis and a small polypoid lesion on the atrophic mucosa of the fundus. A biopsy specimen of the polypoid lesion showed tumor cells with a ribbon or cluster appearance and low-grade atypia (Fig. 1A). The tumor cells were positive for Grimelius silver staining (Fig. 1B). From these data, the polypoid lesion was diagnosed as a carcinoid tumor. However, the finding of non-antral atrophic gastritis suggested that the carcinoid tumor was associated with CAG-A. Indeed, the patients plasma gastrin level was found to be very high (more than $800 \mathrm{pg} / \mathrm{ml}$ ), whereas concentrations of somatostatin, histamine, and serotonin were not elevated. Moreover, serum pepsinogen I and II levels were very low $(7.3$ and $8.5 \mathrm{ng} / \mathrm{ml}$, respectively; I/II ratio, 0.8 ), and testing for anti-parietal-cell antibody was positive, confirming the diagnosis of CAG-A.

Gastrectomy has previously been recommended for such gastric carcinoid tumors [10]; however, patients often reject surgery because their complaint does not seem severe enough to warrant it. We obtained the present patient's informed consent for the lesion to be left untreated under careful observation. In 1991, with the patient's agreement, we decided to perform endo- 


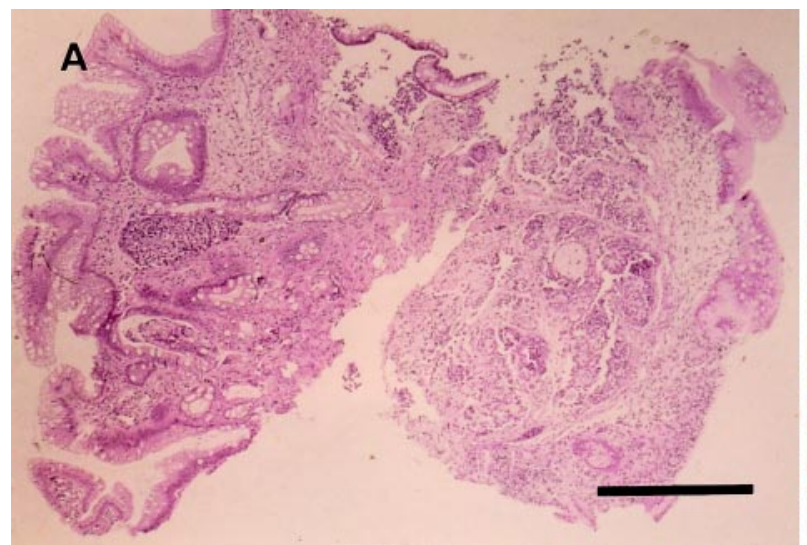

Fig. 1. A Microscopic view of biopsy specimens from gastric polypoid lesion, showing alveolar structures composed of endocrine cells with low-grade atypia. H\&E, Bar, $1 \mathrm{~mm}$. B

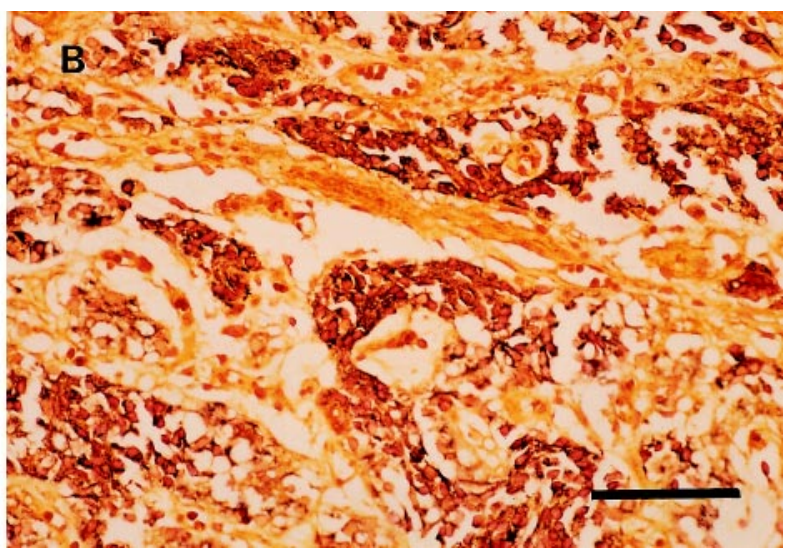

Grimelius-stained section showing argyrophilic granules in the cytoplasm of the tumor cells. Bar, $100 \mu \mathrm{m}$

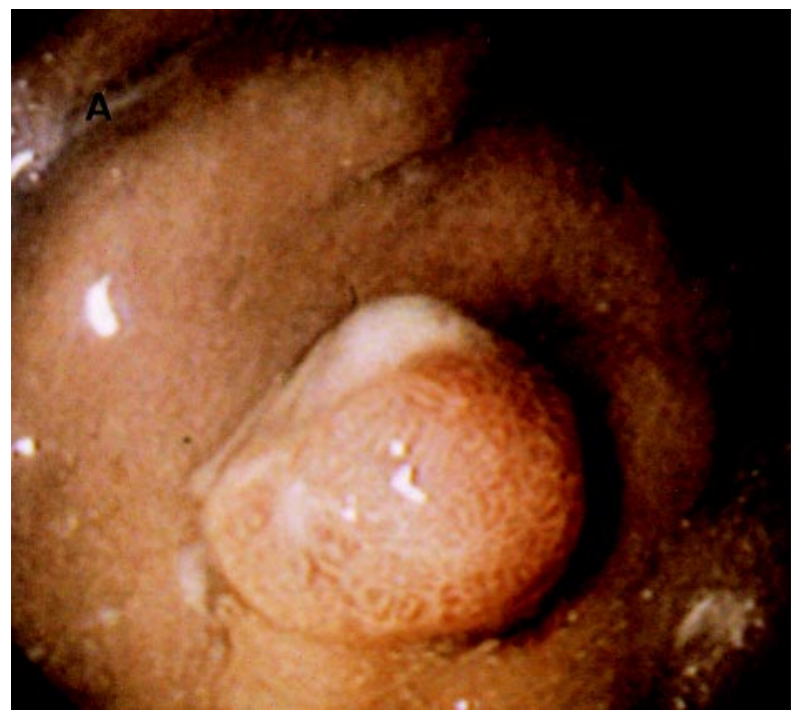

Fig. 2. A Endoscopic view of polypoid lesion on the atrophic fundic mucosa. B Photomicrograph of resected gastric polypoid lesion. The tumor was located mainly in the mucosal

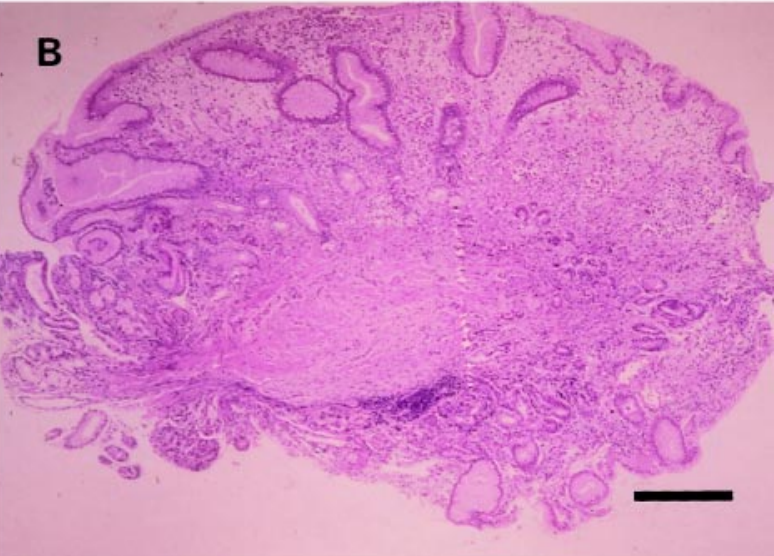

lamina propria and was resected successfully. H\&E, Bar, $1 \mathrm{~mm}$

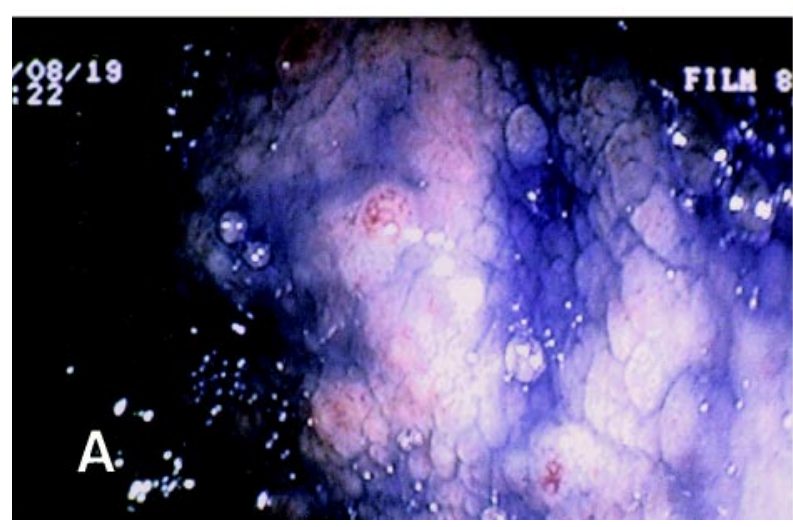

Fig. 4. A Endoscopic view of the fundus after endoscopic mucosal resection (EMR), showing multiple small nodules on atrophic mucosa. B Biopsy specimens from the nodules

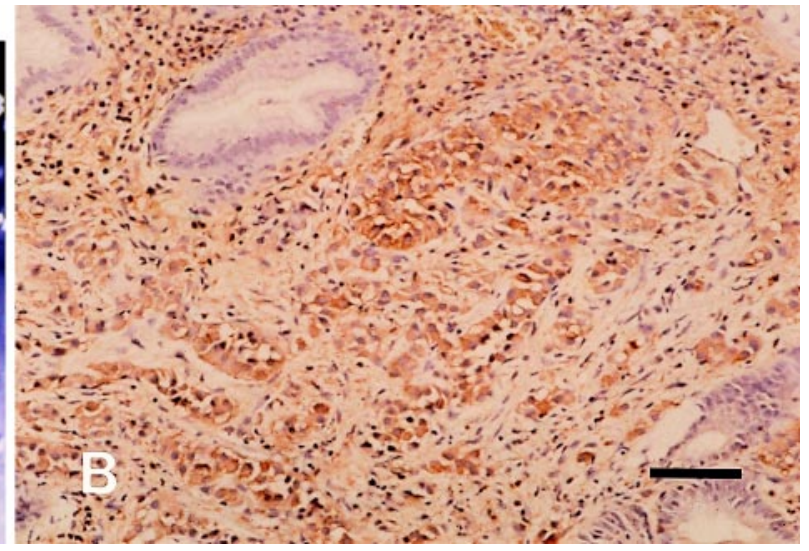

showed endocrine cell hyperplasia and positive immunoreactivity for neuron-specific enolase. Bar, $100 \mu \mathrm{m}$ 
scopic mucosal resection (EMR) of the polypoid lesion because EMR had been reported to be a useful therapy for gastric lesions, including carcinoid tumors [11]. As shown in Fig. 2A, endoscopic examination revealed a polypoid lesion (7-mm diameter) in the fundus of the stomach. After EMR, histological examination showed that the tumor was located mainly in the mucosal lamina propria, and that it had been completely resected (Fig. 2B). After positive Grimelius silver staining, we investigated the origin of the tumor cells, using electron microscopy, and found that they may have originated from enterochromaffin-like (ECL) cells in the fundic mucosa (Fig. 3).

The patient was subsequently followed-up with endoscopic, biochemical, and serological examinations. He showed continuous hypergastrinemia and high levels of histidine decarboxidase in the fundic mucosa $(226.28 \mathrm{fmol} / \mathrm{min}$ per $\mathrm{mg}$ protein; normal range, $120 \pm$ $13 \mathrm{fmol} / \mathrm{min}$ per mg protein) [12]. Although tests for anti-parietal-cell antibody remained positive, anemia was not observed. Regarding Helicobacter pylori infection, neither serological examination nor urease testing was positive for its presence. Follow-up endoscopic examinations invariably revealed multiple small nodules in the fundus (Fig. 4A). Biopsy specimens of these nodules showed endocrine cell hyperplasia that was positively stained by Grimelius silver impregnation, and was also positive for neuron-specific enolase (Fig. 4B). No recurrence or metastasis of the carcinoid tumor was detected during the 12 years of follow-up. The fact that this patient with continuous hypergastrinemia has been free from recurrence or metastasis for 12 years emphasizes the benign nature of carcinoid tumor with CAG-A.

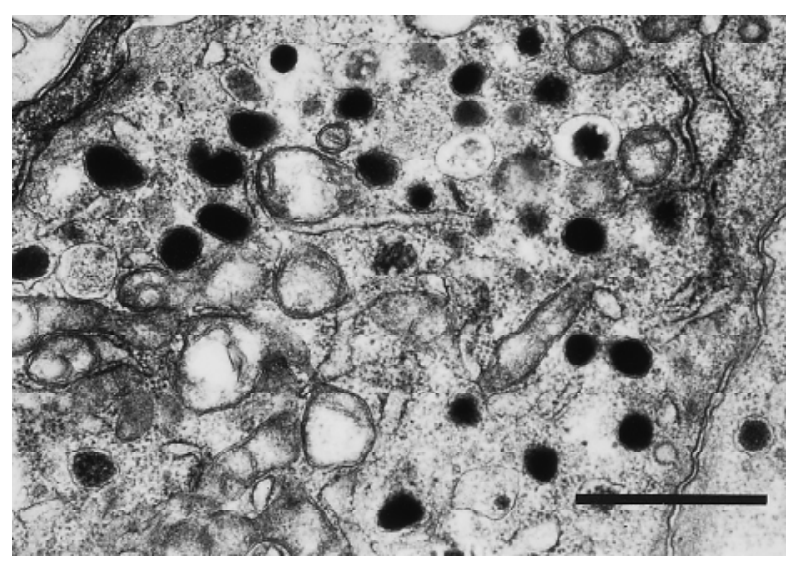

Fig. 3. Electron micrograph of endocrine cell hyperplasia in the corpus mucosa. Secretory granules show an electrolucent halo with uranium-lead stain, which is a characteristic feature of enterochromaffin-like cells. Bar, $1 \mu \mathrm{m}$

\section{Discussion}

Hypergastrinemia is known to cause gastric carcinoid tumors $[13,14]$, up to $75 \%$ of which are associated with CAG-A, which accompanies hypergastrinemia [5,6,15]. Therefore, it is important to investigate the prognosis of gastric carcinoid tumor associated with CAG-A. Recently, gastric carcinoid tumors were classified into three groups on the basis of their clinical characteristics: those associated with CAG-A, those associated with Zollinger-Ellison syndrome, and sporadic carcinoid tumors [6]. With regard to pathological characteristics, CAG-A-associated gastric carcinoid tumor is frequently multiple and smaller than other gastric carcinoids, and is diagnosed as endocrine cell hyperplasia rather than neoplasia. Interestingly, gastric carcinoid tumors associated with CAG-A rarely invade and metastasize, whereas other gastric carcinoid tumors do so frequently $[6,8]$. Moreover, gastric carcinoid tumors associated with CAG-A are not fatal even if they do metastasize $[5,8,9,16]$. Although the reasons for these differences between gastric carcinoids have not yet been clarified, the present case also suggests that gastric carcinoid tumor associated with CAG-A is not likely to metastasize, and that hypergastrinemia may have a good prognosis.

Although there are many kinds of endocrine cells (such as ECL, EC, D, G, A, X, and P cells) in the stomach [17,18], gastric carcinoid tumor associated with hypergastrinemia is believed to originate from ECL cells $[5,6,15]$, which posses gastrin receptors $[19,20]$. This seems likely, because most gastric carcinoid tumors are associated with CAG-A, which accompanies hypergastrinemia, and gastrin is a growth-promoting factor for ECL cells [21,22]. On the other hand, Zollinger-Ellison syndrome is also associated with hypergastrinemia; however, carcinoids associated with Zollinger-Ellison syndrome are relatively malignant compared with CAG-A-associated carcinoids [6,8]. Therefore, we must carefully decide on the treatment for carcinoids associated with MEN type I or ZollingerEllison syndrome, and it may be useful to examine alterations of the menin gene, which is a putative tumor suppressor gene for MEN type I and Zollinger-Ellison syndrome [23], to distinguish between these two types of carcinoids.

Here we have presented a case of CAG-A-associated gastric carcinoid tumor that showed no malignant changes for 12 years, and electron microscopy showed that the tumor may have originated from ECL cell hyperplasia in the fundus. Certainly, electron microscopy is a useful method for confirming the origin of carcinoid tumor; however, this is not easy to employ in a public hospital. Therefore, immunostaining for neuroendocrine cell markers (such as Grimelius silver, 
chromogranin A, and neuron-specific enolase) is recommended for diagnosing carcinoid tumors, although this cannot identify the type of cell from which the tumor has originated. A new specific marker for neuroendocrine cells, especially ECL cells [24,25], will be required to clarify whether CAG-A-associated carcinoids show favorable behavior and should be treated by non-surgical means.

Acknowledgments We thank Dr. Y. Shinomura and Dr. Y. Murayama (Second Department of Internal Medicine, Osaka University School of Medicine, Osaka, Japan) for their help with the electron microscopy.

\section{References}

1. Borsch K, Renvall H, Liedberg G. Gastric endocrine cell hyperplasia and carcinoid tumors in pernicious anemia. Gastroenterology 1985;88:638-48.

2. Moses RE, Frank BB, Leavitt M, Miller R. The syndrome of type A chronic atrophic gastritis, pernicious anemia, and multiple gastric carcinoids. J Clin Gastroenterol 1986;8:61-5.

3. Lehy T, Cadiot G, Mignon M, Ruszniewski P, Bonfils S. Influence of multiple endocrine neoplasia type 1 on gastric endocrine cells in patients with the Zollinger-Ellison syndrome. Gut 1992;33: 1275-9.

4. Solcia E, Capella C, Fiocca R, Rindi G, Rosai J. Gastric argyrophil carcinoidosis in patients with Zollinger-Ellison syndrome due to type 1 multiple endocrine neoplasia: a newly recognized association. Am J Surg Pathol 1990;14:503-13.

5. Rindi G, Bordi C, Rappel S, La Rosa S, Stolte M, Solcia E. Gastric carcinoids and neuroendocrine carcinomas: pathogenesis, pathology, and behavior. World J Surg 1996;20:168-72.

6. Rindi G, Luinetti C, Cornaggia M, Capella C, Solcia E. Three subtypes of gastric argyrophil carcinoid and the gastric neuroendocrine carcinoma: a clinicopathologic study. Gastroenterology 1993;104:994-1006.

7. Rindi G, Azzoni O, Rosa SLA, Klersy C, Paolotti D, Rappel S, et al. ECL cell tumor and poorly differentiated endocrine carcinoma of the stomach: prognostic evaluation by pathological analysis. Gastroenterology 1999;116:532-42.

8. Rappel S, Altendorf-Hofmann A, Stolte M. Prognosis of gastric carcinoid tumours. Digestion 1995;56:455-62.

9. Gilligan CJ, Lawton GP, Tang LH, West AB, Modlin IM. Gastric carcinoid tumors: the biology and therapy of an enigmatic and controversial lesion. Am J Gastroenterol 1995;90:338-52.

10. Morise K, Kusugami K, Hayakawa M, Nakata S, Inagaki T, Hayashi N, et al. Minute carcinoid tumor of the stomach: report of two cases and review of the Japanese literature. Gastroenterol Jpn 1985;20:596-603.

11. Borch K. Atrophic gastritis and gastric carcinoid tumours. Ann Med 1989;21:291-7.

12. Miyazaki Y, Imamura I, Shinomura Y, Wada H, Tarui S. Marked increase in gastric histidine decarboxylase activity in patients with hypergastrinemia. Life Sci 1991;48:51-8.

13. Larsson H, Carlsson E, Mattsson H, Lundell L, Sundler F, Sundell $\mathrm{G}$, et al. Plasma gastrin and gastric ECL cell activation and proliferation: studies with omeprazole and ranitidine in intact and antrectomized rats. Gastroenterology 1986;90:391-9.

14. Larsson H, Carlsson E, Hakanson R, Mattsson H, Nilsson G, Seensalu R, et al. Time-course of development and reversal of gastric endocrine cell hyperplasia after inhibition of acid secretion: studies with omeprazole and ranitidine in intact and antrectomized rats. Gastroenterology 1988;95:1477-86.

15. Kulke MH, Mayer RJ. Carcinoid tumors. N Engl J Med 1999;340:858-68

16. Ahlman H, Kolby L, Lundell L, Olbe L, Wangberg B, Granerus $\mathrm{G}$, et al. Clinical management of gastric carcinoid tumors. Digestion 1994;55:77-85.

17. Sundler F, Håkanson R. Gastric endocrine cell typing at the light microscopic level. In: Håkanson R, Sundler F, editors. The stomach as an endocrine organ. Amsterdam: Elsevier; 1991. pp. 9-26.

18. Capella C. Ultrastructural typing of gastric endocrine cells. In: Håkanson R, Sundler F, editors. The stomach as an endocrine organ. Amsterdam: Elsevier; 1991. pp. 27-52.

19. Chiba T, Kinoshita Y, Morishita T, Nakata H, Nakamura A, Hosoda S. Receptors of gastrin on gastric carcinoid tumor membrane of Mastmys natalensis. Biochem Biophys Res Commun 1991;177:739-44.

20. Nakata H, Matsui T, Ito M, Taniguchi T, Naribayashi Y, Arima N, et al. Cloning and characterization of gastrin receptor from ECL, carcinoid tumor of Mastmys natalensis. Biochem Biophys Res Commun 1992;187:1151-7.

21. Ryberg B, Axelson J, Håkanson R, Sundler F, Mattsson H. Trophic effect of continuous infusion of $\left[\mathrm{Leu}^{15}\right]$-gastrin-17 in the rat. Gastroenterology 1990;98:33-8.

22. Kinoshita Y, Nakata H, Kishi K, Kawanami C, Sawada M, Chiba T. Comparison of the signal transduction pathways activated by gastrin in enterochromaffin-like and parietal cells. Gastroenterology 1988;115:93-100.

23. Chandrasekharappa SC, Guru SC, Manickam P, Olufemi SE, Collins FS, Emmert-Buck MR, et al. Positional cloning of the gene for multiple endocrine neoplasia-type I. Science 1997;276: 404-7.

24. Asahara M, Mushiake S, Shimada S, Fukui H, Kinoshita Y, Kawanami C, et al. Reg gene expression is increased in rat gastric enterochromaffin-like cells following water immersion stress. Gastroenterology 1996;111:45-55.

25. Fukui H, Kinoshita Y, Maekawa T, Okada A, Waki S, Hassan S, et al. Regenerating gene protein may mediate gastric mucosal proliferation induced by hypergastrinemia in rats. Gastroenterology 1998;115:1483-93. 